\title{
Isolated Primary Chylopericardium
}

\author{
Hidetoshi Akashi, MD; Keiichiro Tayama, MD; Kenji Ishihara, MD; Atsuhisa Tanaka, MD; \\ Takayuki Fujino, MD; Teiji Okazaki, MD; Shigeaki Aoyagi, MD
}

\begin{abstract}
A 16-year-old man was found to have an enlarged cardiac silhouette. Primary chylopericardium was diagnosed when pericardiocentesis yielded the characteristic milky-white fluid. The thoracic duct was easily identified by giving milk and butter and an injection of ethylene blue immediately before the operation. Intraoperative thoracic ductography showed no abnormal findings. Mass ligation of the thoracic duct above the diaphragm and partial pericardiectomy were successfully performed through a right thoracotomy approach. In addition, many of the lymphatics were ligated above the diaphragm. The right thoracotomy approach was a useful method for resection and ligation of the thoracic duct just above the diaphragm. Follow-up showed no accumulation of pericardial fluid or pleural effusion. (Jpn Circ J 1999; 63: 59-60)
\end{abstract}

Key Words: Primary chylopericardium; Right thoracotomy; Surgical treatment

$\mathbf{P}$ rimary chylopericardium is an infrequent clinical condition. It is generally congenital in origin or may be caused by caval obstruction!,2 In 1954 Groves and Effler suggested the term 'primary chylopericardium' for cases in which no etiologic mechanism could be demonstrated? The exact cause of the disorder in the idiopathic cases is still unknown. Current therapeutic options include dietary treatment, serial pericardiocentesis, pericardial-peritoneal shunts, pericardiectomy, and thoracic duct ligation $1,2,4$ We describe a patient with isolated primary chylopericardium who underwent surgery with a successful result.

\section{Case Report}

A 16-year-old man, who had been asymptomatic for many years, was referred to hospital for examination of cardiomegaly (cardiothoracic ratio, 0.6). He had no history of chest trauma or thoracic operation. Massive pericardial effusion was detected by echocardiography. Neither chest radiography nor computed tomography showed evidence of intrathoracic lesions with tumor masses (Fig 1). The diagnosis of primary chylopericardium was established by an analysis of the $125 \mathrm{ml}$ of milky-colored chylous fluid obtained by pericardiocentesis. Two months after the pericardiocentesis, chest radiography again showed an enlarged cardiac silhouette.

One hundred grams of butter and $200 \mathrm{ml}$ of milk was given orally $3 \mathrm{~h}$ before the operation and in addition, $2 \mathrm{ml}$ of ethylene blue was injected under the skin of the left lower limb $1 \mathrm{~h}$ before operation. Surgical treatment was performed through a posterolateral right thoracotomy in the sixth intercostal space. After the right lower lobe was mobilized, the tissue between the azygos vein and the esophagus was peeled off. The milky-greenish thoracic duct was easily found immediately above the diaphragm

(Received April 22, 1998; revised manuscript received September 28, 1998; accepted September 29, 1998)

Department of Surgery, Kurume University School of Medicine, Kurume, Japan

Mailing address: Hidetoshi Akashi, MD, The Department of Surgery, Kurume University School of Medicine, 67 Asahi-machi, Kurume 830, Japan

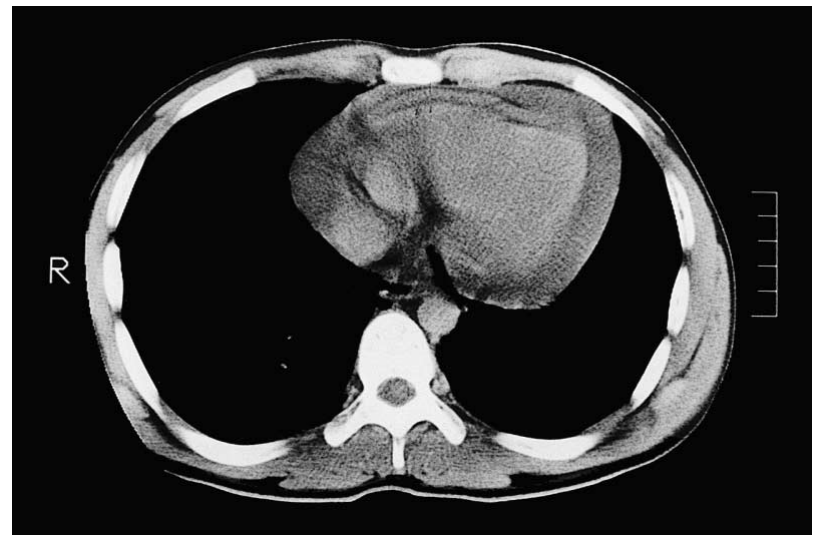

Fig 1. Pre-operative computed tomography revealed accumulation of a large volume of chylous fluid in the pericardium.

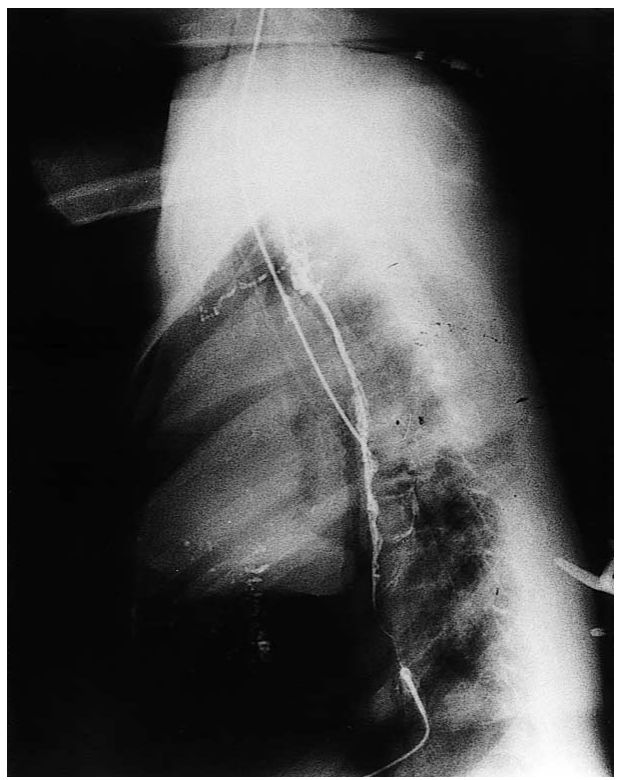

Fig 2. Intraoperative lymphangiogram showing the thoracic duct located in front of the spinal column without direct communication to the pericardium. 
without mobilization of the esophagus. Intraoperatve thoracic ductography showed no abnormal findings (Fig 2). Ligation and resection (14 cm length) of the thoracic duct were performed. A pericardial window $(5 \times 5 \mathrm{~cm})$ was also made to release $400 \mathrm{ml}$ of chylous fluid into the right pleural space. In addition, many lymphatics were ligated above the diaphragm and the edges of the pericardial window were tightened by 4-0 Prolene. Immediately after the operation, no chylous fluid was aspirated from the drainage tube and the serous fluid drainage decreased markedly. He was discharged from the hospital without dietary treatment on the 14th postoperative day and was remarkably well 2 months later. Follow-up by echocardiography showed no accumulation of the pericardial fluid or pleural effusion.

\section{Discussion}

Primary chylopericardium is an uncommon entity and the exact pathophysiology has not been elucidated. However, it has been reported that reflux of chylous fluid into the pericardial cavity is the main mechanism. It has been suggested that the presence of damage to valves of the thoracic duct and to its communication to the pericardial lymphatics results in chylous reflux and elevation of the intraluminal pressure in the thoracic duct observed as lymphangiectasia. Therefore, certain congenital abnormalities of the lymphatic system might be involveds

The treatment of choice for all patients with symptoms is surgical exploration, including thoracic duct ligation and partial pericardiectomy!,2 As well, 'mass ligation above the diaphragm' is recommended because of wide anatomic variations in the course of the duct in this region and because of the indistinct cause of primary chylopericardium.6,7 Akamatsu et al presented 2 illustrative cases and an in-depth analysis of recurrence along with a suitable surgical procedure? In their paper, they reported that in a collective review of the literature 2 in 22 patients who received ligation and resection of the thoracic duct and establishment of a pericardial window through a right thoracotomy showed reaccumulation of the chylous fluid. However, there was no reaccumulation of the chylous fluid in patients receiving left thoracotomy. They also reported that the left thoracotomy approach had many advantages over the right approach for performing both ligation and resection of the thoracic duct, even though the thoracic duct ran along the right side of the descending aorta. However, we undertook the right thoracotomy approach in our case for the following 3 reasons. First, anatomically the lower thoracic duct ran right behind the esophagus and the right side of the descending aorta. Second, the lower thoracic duct was more easily ligated and resected widely just above the diaphragm, and third, the lower thoracic duct could be reached less invasively by a right thoracotomy approach with minimal dissection by isolating the descending aorta and the esophagus. In our case, using the right thoracotomy approach, the thoracic duct, which was milky-greenish, ran between the azygos vein and the esophagus. We could easily and less invasively ligate and resect the thoracic duct without mobilizing the azygos vein and the esophagus. We also were able to create a pericardial window without compressing the heart.

As demonstrated by this case, the thoracic duct was easily identified by oral administration of milk and butter and injection of ethylene blue before the operation. In addition, mass ligation of the thoracic duct above the diaphragm and partial pericardiectomy were successfully performed through a right thoracotomy approach.

\section{References}

1. Dunn RP: Primary chylopericardium: A review of the literature and an illustrated case. Am Heart J 1975; 89: 369-377

2. Chan BB, Murphy MC, Rodgers BM: Management of chylopericardium. J Pediatr Surg 1990; 25: 1185-1189

3. Groves LK, Effler DB: Primary chylopericardium. $N$ Engl J Med 1954; 250: $520-523$

4. Harada K, Takigawa I, Toyoda H, Okada T, Usami H: Primary chylopericardium recovered without surgical treatment: report of a case and review of the literature. Jpn Circ J 1982; 46: 162-171

5. Nagamura Y, Takahashi S, Hirosawa K, Konno S, Hashimoto M, Okamura K: A case of primary chylopericardium. Naika 1978; 42: $141-144$

6. Gao CX: Surgical management of chylothorax: a report of 65 cases. Chung Hua Wai Ko Tsa Chih 1989; 27: 164-165, 189

7. Gallant TE, Hunziker RJ, Gibson TC: Primary chylopericardium: the role of lymphangiography. Am J Roentgenol 1977; 129: $1043-1045$

8. Akamatsu H, Amano J, Sakamoto T, Suzuki A: Primary chylopericardium. Ann Thorac Surg 1994; 58: 262-266

9. Irie Y, Yamada M, Suzuki O, Murai N, Tanabe S, Oshima N, et al: Primary chylopericardium: A case report. Kyobugeka 1993; 46: $472-476$ 